\title{
El rururbano de la ciudad de Bahía Blanca (provincia de Buenos Aires, Argentina): ¿residentes vulnerables a los cambios?*
}

\section{The rururban of the city of Bahía Blanca: ¿Are residents vulnerable to change?}

\section{Claudia Sereno}

Doctora en Geografía. Departamento de Geografía y Turismo. Universidad Nacional del Sur (UNS). 12 de octubre 991, oficina 07, int. 2907, (8000) Bahía Blanca, Buenos Aires, Argentina, csereno@uns.edu.ar, ORCID https://orcid.org/0000-0002-2986-6807

Recibido: 6 de marzo 2020 || Aprobado: 21 de julio 2020

Resumen

La ciudad de Bahía Blanca experimenta, en los últimos años, una expansión del suelo urbano hacia la periferia sufriendo alteraciones, en particular, de sus bordes. En este sentido, los residentes más antiguos del rururbano bahiense, dedicados a tareas agropecuarias, son vulnerables -debido al crecimiento de usos incompatibles, en general, con sus rutinas- y a través de sus prácticas cotidianas, demuestran arraigo y tendencia a permanecer o desarraigo y disposición a abandonar sus propiedades. El trabajo identifica los impactos de la urbanización en el área y la percepción de sus pobladores respecto a esta situación, así como establece la vulnerabilidad, en especial, de los pobladores más antiguos cuyas decisiones y estrategias incidirán en la tendencia al cambio del borde. La metodología combina técnicas cuali-cuantitativas y está basada, en el trabajo en el terreno, la aplicación de entrevistas semiestructuradas a los pobladores y la incorporación de los datos en un SIG para confeccionar la cartografía síntesis de vulnerabilidad.

Palabras clave: Rururbano; Vulnerabilidad; Expansión urbana; Residentes rurales

\section{Abstract}

The city of Bahía Blanca has experienced, in recent years, an expansion of the urban land towards the periphery, suffering alterations, in particular, of its edges. In this sense, the oldest residents of the urban bahiense, dedicated to rural tasks, are vulnerable -due to the growth of uses incompatible, in general, with their routines- and through their daily practices and ties, they show roots and tendency to remain or uproot and, therefore, willingness to abandon their properties. The work identifies the impacts of urbanization in the area and the perception of its residents regarding this situation, as well as establishing the vulnerability, especially, of the oldest inhabitants whose decisions and strategies will influence the tendency to change the edge. The methodology combines qualitative-quantitative techniques and is based, in the field work, on the application of semi-structured interviews to the inhabitants and the incorporation of the data in a GIS to prepare the vulnerability synthesis cartography in the area.

Key words: Rururban areas; Vulnerability; Urban expansion; Rural residents

* Este trabajo es realizado en el marco del proyecto "Los espacios locales y regionales como una construcción socio-cultural. Análisis multiescalar" financiado por la Secretaria de Ciencia y Tecnología de la Universidad Nacional del Sur.

Cita sugerida: Sereno, C. (2020). El rururbano de la ciudad de Bahía Blanca (provincia de Buenos Aires, Argentina): ¿residentes vulnerables a los cambios? Estudios Socioterritoriales. Revista de Geografía, (28), 063. DOI: https://doi.org/10.37838/unicen/est.28-063 


\section{INTRODUCCION}

El espacio geográfico -soporte de las interrelaciones sociales y naturales- está sujeto a un proceso dinámico de transformaciones continuas que generan áreas con características disímiles y diferenciadas, como el ámbito rural y el urbano. Sin embargo, no existe una ruptura abrupta entre estos dos entornos, sino que emergen espacios de transición singulares, con características específicas que dan testimonio de esta continuidad de funciones, relaciones, oportunidades y conflictos. El rururbano como uno de estos ámbitos transicionales, es entendido como la franja externa del periurbano, una zona de avance de la ciudad, aunque de forma incipiente, con predominio de usos rurales, complementados con los urbanos y donde existe un interjuego de lógicas urbanas-rurales que lo transforman en un escenario de conflictos ambientales y económicos, por mencionar algunos (González Plaza, 2006; García Ramón, Tulla I Pujol y Valdovinos Perdices, 1995; Entrena citado por Zuluaga Sánchez, 2005; Bozzano, 2000; Barsky, 2005; Feito 2018; Sereno, Santamaría y Santarelli, 2010). Es un espacio signado por un modo de vida propio -relacionado a una red de prácticas cotidianas y representaciones del espacio construidas en el tiempo (Caroux, Pitrou y Juan citados en Lindón, 2002a; Lindón, 1999)-, vulnerable debido a la expansión de usos urbanos, industriales y de servicios, donde los residentes -en especial aquellos dedicados a actividades agropecuarias- a través del ejercicio de sus prácticas cotidianas, sentimientos y nexos, demuestran arraigo y tendencia a permanecer o desarraigo y, por lo tanto, disposición a abandonar sus propiedades. En este sentido, las configuraciones territoriales de estos bordes ${ }^{1}$ se explican por el avance de ciertas formas socio-espaciales sobre otras $y$, en especial, por los cambios en los modos de vida resultantes de los procesos económicos y socioambientales que la expansión de la ciudad provoca y por las decisiones que toman sus residentes sobre el uso y ocupación del espacio guiadas por las representaciones mentales que elaboran en el transcurrir cotidiano.

Es necesario aclarar que muchas de las transformaciones asociadas a la expansión urbana en las periferias responden al proceso de globalización que modifica las relaciones campo-ciudad y permite que áreas agrícolas adquieran nuevas fisonomías a partir de procesos de urbanización del agro y del cambio tecnológico; así como favorece el movimiento de habitantes urbanos que buscan satisfacer sus necesidades en el campo y homogeniza modelos de organización del espacio geográfico (De Mattos, 1999; Martínez Borrego, 2008; Ávila Sánchez, 2009; García Ramón et al., 1995).

$\mathrm{Al}$ indagar en los estudios sobre los ámbitos rururbanos existen investigaciones que reconocen este espacio y lo diferencian, desde su configuración espacial como social, del periurbano próximo a la ciudad (Entrena citado por Zuluaga Sánchez, 2005; Arango Escobar, 2008; González Escobar, 2003). Asimismo, Barros (1997; 1999; 2000) introduce fundamentos para el estudio de los espacios de frontera -el rururbano entre ellos- y pone atención en los procesos sociales que se desarrollan en este ámbito, haciendo referencia a la construcción del lugar como espacio vivido; su reflexión se complementa con las

1 Bozzano introduce el concepto de territorios de borde como aquellos ámbitos “... donde los efectos de aglomeración urbana se reducen o son menos evidentes, particularidad que no implica necesariamente la disminución gradual en la intensidad de ocupación residencial..." (2000, p. 85). Asimismo, sostiene que en ellos se da un interjuego de lógicas económicas, sociales y ambientales particulares. El autor identifica estos espacios tanto en intersticios urbanos como en espacios periurbanos (Bozzano, 2000). El rururbano objeto de estudio de esta presentación constituye un territorio de borde en espacios periurbanos. 
indagaciones de Lindón (2002a; 2002b; 2003; 2005) sobre la periferia como espacios cotidianos. Entre los trabajos más recientes, es dable mencionar la exposición de Nates Cruz (2018) sobre territorialidades rururbanas concebidas como un tercer territorio distinguido por la existencia de nuevas formas de apropiar, vivir y entender el espacio, que dan lugar a un modo de vida distinto al rural o al urbano; el artículo de Sánchez Torres (2018) sobre las perspectivas teórico-metodológicas utilizadas para definir este espacio y las múltiples dimensiones de análisis del mismo; así como las investigaciones sobre sistemas rururbanos y vulnerabilidad de Cardozo (2018) quien establece un índice de vulnerabilidad socioambiental; de Jorquera Limón y Gálvez Andrade (2018) y de Moreno Mata, Cárdenas Nielsen y Sánchez del Toro (2018) ambos enfocados en las consecuencias de la urbanización en las periferias, ya sea para las actividades agropecuarias en estos ámbitos como en su configuración espacial.

Todos estos valiosos aportes permiten plantear distintos interrogantes asociados a la comprensión de los procesos en las áreas de avance, en especial, en el rururbano de la ciudad de Bahía Blanca tales como ¿qué caracteriza a los pobladores del rururbano?, ¿cuáles son sus vivencias y significados?, ¿cómo perciben los cambios relacionados a la expansión urbana y de qué manera responden a las transformaciones que caracterizan su espacio vivido²?, ¿qué estrategias implementan para adaptarse a los mismos?, ¿cuán vulnerable son a los cambios provocados por la expansión urbana?

Bahía Blanca constituye una ciudad intermedia que se encuentra en el partido homónimo, localizado en el sudoeste de la provincia de Buenos Aires, limitado al oeste por el partido de Villarino y Tornquist, al norte por el partido de Tornquist, al este por los partidos de Coronel Pringles y Coronel de Marina L. Rosales y al sur con este último, el estuario de Bahía Blanca y el partido de Villarino (Figura 1). Esta localidad cuenta con una población de 296 mil habitantes (INDEC, 2010) y con un número importante de servicios culturales, educativos, administrativos, comerciales, recreativos y sanitarios que ofrece, también, para una extensa región circundante; mientras que la actividad económica del entorno es considerada de perfil agrícola e industrial. En los últimos años se observa una expansión del suelo urbano hacia la periferia con una ocupación de baja densidad -entre 1991-2010 la superficie urbana ocupada creció un 89\% (Urriza, 2018)- sufriendo, en consecuencia, alteraciones internas de sus elementos constitutivos $y$, en particular, de sus bordes, aspectos que han originado desequilibrio y conflictos estructurales y sociales.

En este contexto, el trabajo tiene como objetivos conocer los impactos de la urbanización en el área, en particular el sector norte, noreste, noroeste y este ${ }^{3}$ (Figura 1) y la percepción de sus pobladores respecto a esta situación, así como establecer la vulnerabilidad, en especial, de los pobladores más antiguos -y dedicados, en general, a tareas agropecuarias intensivas o extensivas- cuyas decisiones y estrategias incidirán en la tendencia al cambio del borde.

2 Espacios cotidianos, cargados de sentidos similares o diferentes al resto -pluralidades de sentido-, y donde lo simbólico -representaciones, imágenes, significados- y el tiempo, que es el de las prácticas diarias, se enmarca, a su vez, en un tiempo histórico (Di Meo, 1999; Lindón, 2003).

3 Se seleccionan solo estos sectores del rururbano porque poseen la mejor aptitud para el avance de la urbanización, teniendo en cuenta el estudio realizado por Zinger, del Pozo y de Gaetano (1990). La sectorización del área de estudio se realizó sobre la base de la delimitación de Formiga (1997) con el propósito de facilitar la interpretación de los resultados. 
La primera parte del artículo describe las etapas metodológicas en la investigación, destacando las variables y dimensiones de estudio, así como las técnicas de recopilación y análisis de datos empleadas; en el segundo apartado, se desarrolla el marco conceptual relacionado al tema objeto de estudio; en tercer lugar, se caracteriza el rururbano de la ciudad de Bahía Blanca, desde su configuración espacial como social; en la cuarta sección, se realiza una síntesis sobre el impacto de los planes urbanos de los últimos años en la ciudad sobre el área de estudio y se le otorga especial interés al relato de las vivencias y percepciones de los cambios de sus pobladores; por último, se aborda la vulnerabilidad de los residentes del área a través del análisis de la cartografía temática y síntesis.

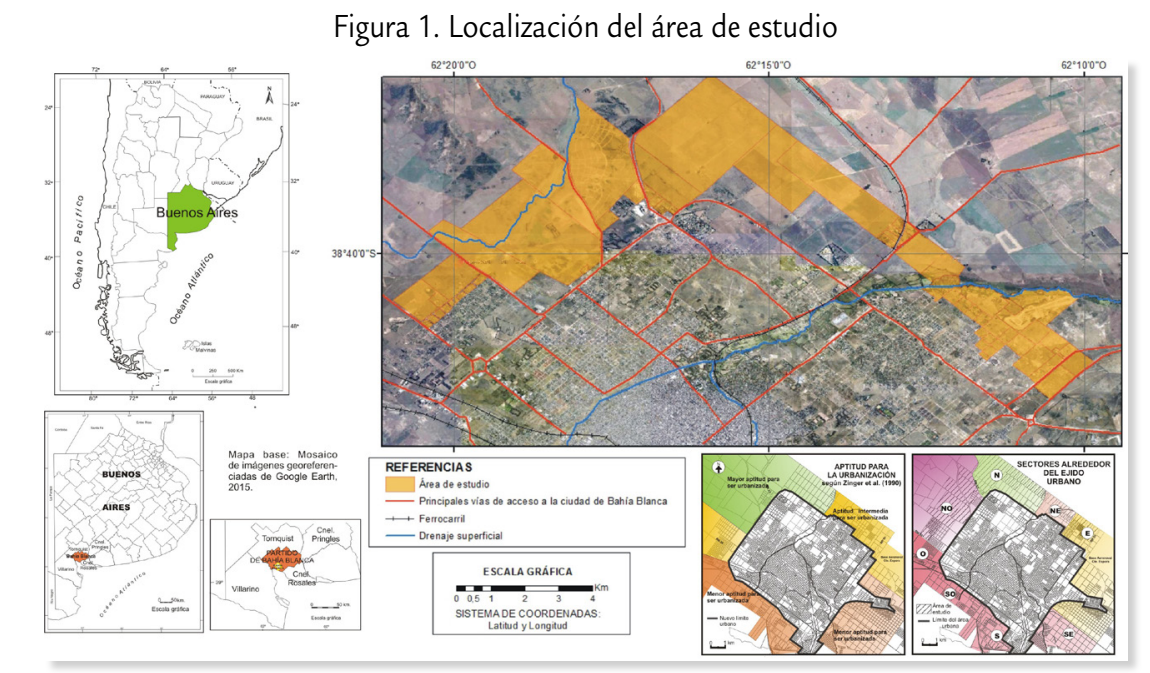

Fuente: elaboración personal con base en relevamientos en el terreno, zonificación de Bahía Blanca (Municipalidad de Bahía Blanca) y clasificación de imágenes satelitales

\section{METODOLOGíA Y TÉCNICAS}

La metodología empleada en este trabajo se sustenta en la combinación de técnicas cuali-cuantitativas. Para la recolección de datos se utilizó la observación en el terreno y las entrevistas semiestructuradas a los residentes del área. El primer procedimiento se realizó para conocer las características propias, diferenciar paisajes y detectar los efectos de la urbanización creciente en este ámbito. En cuanto al segundo instrumento de recolección se realizaron un total de 26 entrevistas: 22 se aplicaron a propietarios o arrendatarios dedicados a tareas rurales intensivas, hornos de ladrillo, prestadores de servicios rurales y antiguos residentes del borde -es decir aquellos dedicados a actividades cuya permanencia es difícil frente al avance urbano-; y se realizaron a nuevos residentes del área. Las mismas permiten comprender la cotidianidad y la percepción de sus habitantes sobre los cambios socioespaciales del área; así como recopilar las variables de análisis (distancia a la ciudad, tenencia de la tierra, actividades realizadas, tipo de anclaje territorial, estrategias empleadas, expectativas, calificación de los vínculos sociales y disposición para abandonar la propiedad) que luego se incorporan a un Sistema de Información Geográfico (SIG) para obtener la vulnerabilidad en el área de estudio. La recopilación se efectuó mediante un muestreo teórico, no probabilístico, en el cual se combina la modalidad de "juicio experto" y "bola de nieve", método que permitió seleccionar las unidades de análisis. 
Para el tratamiento de los datos cuali-cuantitativos se estimó adecuado aplicar un SIG -ArcGis 10.1-. Las etapas de tratamiento de los datos se detallan en los siguientes ítems:

1) confección de la cartografía base, que incluye la captura de imágenes de Google Earth, la georreferenciación de las mismas y la construcción de un mosaico base;

2) selección de las variables que surgen de la observación de las respuestas de los entrevistados. Al tratarse de variables cualitativas se procedió, en primer lugar, a examinar las respuestas de cada entrevista para cada variable de análisis, luego se generalizaron las expresiones para establecer una escala de clases para cada una (Tablas 1 y 2). La escala unificadora para todas ellas va del 1 al 4 , donde 4 corresponde a aquellos aspectos que acrecientan la vulnerabilidad y 1 a las respuestas que disminuyen la vulnerabilidad;

3) diseño de la tabla de atributos. En el caso de los productores agropecuarios, se tomó la propiedad como base espacial para cargar los datos, mientras que para aquellos entrevistados que habitan en zonas de parcelamiento urbano, la unidad para cargar los datos fue la manzana donde se localizan.

4) representación de las variables en forma individual. Confección e interpretación de cartografía temática;

5) conversión de las bases de formato vectorial a ráster;

6) aplicación de la función de procesamiento espacial para elaborar los mapas temáticos de vulnerabilidad. Se utilizaron dos herramientas de análisis espacial de ArcGis: la superposición ponderada ${ }^{4}$ y la calculadora ráster ${ }^{5}$. Se decidió adoptar como base para asignar el porcentaje de influencia de las variables lo establecido en las conceptualizaciones teóricas de Wilches-Chaux (1993) que menciona la vulnerabilidad económica, social y cultural, física y técnica. Se confeccionaron distintos mapas para cada tipo de vulnerabilidad. En la primera superposición se otorgó mayor peso (\% de influencia) a las variables relacionadas con la vulnerabilidad económica (disposición de irse del rururbano, tipo de actividades y estrategias empleadas); en la segunda, a las asociadas con la vulnerabilidad social y cultural (tipo de vínculo, tipo de anclaje y expectativas); en la tercera, a las vinculadas con la vulnerabilidad física (distancia al centro de la ciudad) y en la última a las ligadas a la vulnerabilidad técnica (estrategias empleadas) (Tabla 2).

7) elaboración del cartograma síntesis de vulnerabilidad;

8) reclasificación de los resultados. El ráster obtenido fue simplificado a tres clases, agrupando los valores más bajos, los medios y los más altos;

9) Interpretación de los resultados de los mapas temáticos y síntesis obtenidos. La Figura 2 sintetiza las etapas detalladas anteriormente.

4 La superposición ponderada se basa en la combinación de tres tareas: Ingreso de shape ráster reclasificados según una misma escala; multiplicación de los valores de cada celda por el peso de importancia otorgado y suma de los valores por celda para generar un ráster de resultados final (ESRI, 1995-2012).

5 Procedimiento que permite aplicar operaciones matemáticas como la suma de dos o más ráster, la extracción de píxeles de un ráster basado en un criterio específico, la comparación de un ráster con otro, aplicar diversas funciones a uno o más ráster. En el caso particular de estudio se aplicará la suma de distintos ráster para obtener un producto de salida con la totalidad de los valores sumados por celda (ESRI, 1995-2012). 
Tabla 1. Descripción de las variables de análisis

Las actividades se clasificaron en cuatro dimensiones en función de los datos recolectados a través de las entrevistas: actividad rural in-

Actividades tensiva o extensiva, actividad ladrillera, prestador de servicios rurales realizadas y trabajo en la ciudad. Para asignarles el valor correspondiente se considera que aquellas relacionadas al ámbito rural tienen mayor riesgo de desaparecer ante las presiones urbanas y, como consecuencia, los habitantes que las practican presentan mayor vulnerabilidad.

Disposi- Se clasificó esta variable teniendo en cuenta las opiniones vertidas ción para en las entrevistas entendiendo que el residente que opta por irse, es abandonar aquel con menor capacidad para enfrentar los cambios o el que prela pro- senta menos arraigo a la propiedad y a la actividad que realiza $y$, por piedad lo tanto, es más vulnerable.

Se determina teniendo en cuenta la plaza principal de la ciudad y se

Distancia

al cencalcula, aproximadamente, la distancia de las propiedades del área de tro de la ciudad estudio a la misma.

Para asignar el valor que corresponde a cada dimensión se entiende que las propiedades más alejadas del centro de la ciudad presentan menor riesgo de ser captadas por la expansión urbana y como consecuencia son menos vulnerables.

Los residentes del rururbano presentan un modo de vida con rutinas y ritmos propios que los identifican $y$, ante la presión urbana, son motivados a responder a una estructura de normas, modos y ritmos diferentes, adoptando diversas estrategias como respuestas. Las estrategias son clasificadas siguiendo los conceptos vertidos por el Centro Latinoamericano y Caribeño de Demografía (CELADE, 2002), Hernández Montesinos (2001) y Tacoli (2003) en estrategias de acumulación (tendientes a incorporar valor a la producción, ya sea por extensión de las actividades o especulación), estrategias de sobrevivencia (asociadas con escasos recursos para enfrentar la situación y persistir en la actividad agropecua-

Estrategias empleadas ria, lo que obliga a la diversificación en otras actividades) y abandono. Entre las estrategias de acumulación que practican los residentes del rurubano bahiense están: diversificar la actividad dentro de la propiedad; contratar servicios de terceros; implementar nuevas técnicas; recibir asesoramiento; entre otras); mientras que las estrategias de sobrevivencia que los entrevistados del área mencionan son: apostar por la educación de sus hijos; transmitir valores y amor por las labores rurales y por la propiedad a hijos y nietos; implementar actividades extra prediales; ser creativos, entre otras.

Para la asignación de un valor a cada dimensión, se entiende que aquellos que implementan las primeras están más preparados-dado los recursos económicos y materiales- para enfrentar los cambios y, como consecuencia, son menos vulnerables.

Para ponderar esta variable se entiende que cuando las expectativas están centradas en la permanencia (ya sea conservando o exExpec- pandiendo la actividad) constituyen un potencial que incide en la tativas implementación de estrategias para mantener la propiedad y actividad; y como consecuencia, disminuye la vulnerabilidad de aquellos que presentan este tipo. 
El anclaje territorial en el rururbano bahiense se relaciona a estar aferrado a determinadas prácticas y rutinas cotidianas, a un ritmo de vida y al mantenimiento de relaciones locales propias de un ámbito de borde. Constituye un aspecto clave para comprender las respuestas de cada actor social ante distintas circunstancias (Cañón, 2014; Jungemann, 2008; Avalle, 2009; Riou, 2011). Se generaron cuatro dimensiones de anclaje territorial siguiendo las conceptualizaciones teóricas de Riou (2011) y los datos recolectados a través de las entrevistas. Así están los 'enamorados del lugar' (nacidos en este espacio que están o han estado dedicados a trabajos en el ámbito rural heredados de sus padres o abuelos. Eligen sectores con las características del campo para habitar, sus expectativas se centran en conservar estos ámbitos y rechazan el avance de la ciudad), los 'forzados por razones familiares

Tipo de o laborales' (no han elegido el rururbano para vivir, sino que cuesanclaje tiones laborales o personales los obligan a emplazarse en el borde), territorial 'los que evalúan irse del rururbano' (aman el lugar y la actividad a la que se dedican -ganadería intensiva o extensiva u horticultura- pero debido a la incompatibilidad de sus tareas con el aumento de población que sufren estas áreas deben desplazarse de manera obligada. El crecimiento urbano se percibe como una amenaza para la continuidad de sus labores) y aquellos 'en proceso de formación de anclaje territorial' (recientemente han elegido el borde para vivir, pobladores urbanos que huyen del ritmo de la urbe atraídos por las condiciones del área; sin embargo, sus trabajos son urbanos y viajan diariamente a la ciudad para cumplir sus obligaciones).

Se entiende que cuanto mayores son los vínculos con el lugar y con los pobladores del área, menor disposición al cambio y vulnerabilidad tendrán los habitantes del rururbano y, como consecuencia, implementarán distintas estrategias de permanencia en el lugar.

El rururbano perdura a partir del tipo de vínculos que los residentes entablan con el lugar y entre pares, vínculos que, por un lado, afianzan

Calificación de los vínculos sociales los sentimientos de arraigo y, por otro, 'deslocalizan' o desvinculan a los individuos cuando adoptan una lógica de comportamiento y reglas particulares. Estos lazos se convierten, en combinación con el sentido de pertenencia y arraigo al lugar, en potencialidades que capacitan a los residentes del rururbano para enfrentar con éxito los procesos de transformación. Se entiende que cuanto mayores son los vínculos, mayor será el arraigo al lugar y menor la vulnerabilidad.

Se construyeron dimensiones en función de los datos recolectados a través de las entrevistas: Propietario con más de 10 años; propietario de menos de 10 años; empleado y arrendatario.

Tenencia Para establecer el valor de cada dimensión, se entiende que aquel prode la tierra pietario con mayor antigüedad en el área está menos dispuesto a vender su propiedad o transformar su actividad frente al avance urbano $y$, como consecuencia utilizará todos sus activos materiales y recursos para conservarla.

Fuente: elaboración personal, 2019 
Tabla 2. Ponderación de las variables de análisis

\begin{tabular}{|c|c|c|c|c|c|c|c|c|c|}
\hline \multirow[b]{2}{*}{ Variable } & \multirow[b]{2}{*}{ Dimensión } & \multicolumn{2}{|c|}{$\begin{array}{l}\text { Vulnerabilidad } \\
\text { económica }\end{array}$} & \multicolumn{2}{|c|}{$\begin{array}{l}\text { Vulnerabilidad } \\
\text { social y cultural }\end{array}$} & \multicolumn{2}{|c|}{$\begin{array}{l}\text { Vulnerabili- } \\
\text { dad física }\end{array}$} & \multicolumn{2}{|c|}{$\begin{array}{l}\text { Vulnerabili- } \\
\text { dad técnica }\end{array}$} \\
\hline & & $\begin{array}{l}\text { Valor } \\
\text { de la } \\
\text { escala }\end{array}$ & $\begin{array}{l}\% \text { In- } \\
\text { fluen- } \\
\text { cia }\end{array}$ & $\begin{array}{l}\text { Valor } \\
\text { de la } \\
\text { escala }\end{array}$ & $\begin{array}{l}\% \text { In- } \\
\text { fluen- } \\
\text { cia }\end{array}$ & $\begin{array}{l}\text { Valor } \\
\text { de la } \\
\text { escala }\end{array}$ & $\begin{array}{l}\% \text { In- } \\
\text { fluen- } \\
\text { cia }\end{array}$ & $\begin{array}{l}\text { Valor } \\
\text { de la } \\
\text { escala }\end{array}$ & $\begin{array}{c}\% \text { In- } \\
\text { fluen- } \\
\text { cia }\end{array}$ \\
\hline \multirow{4}{*}{$\begin{array}{l}\text { Activi- } \\
\text { dades } \\
\text { realizadas }\end{array}$} & $\begin{array}{l}\text { Actividad } \\
\text { rural intensi- } \\
\text { va o extensiva }\end{array}$ & 4 & \multirow{4}{*}{25} & 4 & \multirow{4}{*}{5} & 4 & \multirow{4}{*}{5} & 4 & \multirow{4}{*}{10} \\
\hline & $\begin{array}{l}\text { Actividad } \\
\text { ladrillera }\end{array}$ & 3 & & 3 & & 3 & & 3 & \\
\hline & $\begin{array}{l}\text { Prestador } \\
\text { de servicios } \\
\text { rurales }\end{array}$ & 2 & & 2 & & 2 & & 2 & \\
\hline & $\begin{array}{l}\text { Trabaja en } \\
\text { la ciudad }\end{array}$ & 1 & & 1 & & 1 & & 1 & \\
\hline \multirow{4}{*}{$\begin{array}{l}\text { Disposi- } \\
\text { ción para } \\
\text { aban- } \\
\text { donar la } \\
\text { propie- } \\
\text { dad }\end{array}$} & $\mathrm{Si}$ & 4 & \multirow{4}{*}{25} & 4 & \multirow{4}{*}{5} & 4 & \multirow{4}{*}{5} & 4 & \multirow{4}{*}{10} \\
\hline & Puede ser & 3 & & 3 & & 3 & & 3 & \\
\hline & No responde & 2 & & 2 & & 2 & & 2 & \\
\hline & No & 1 & & 1 & & 1 & & 1 & \\
\hline \multirow{4}{*}{$\begin{array}{l}\text { Distancia } \\
\text { al centro } \\
\text { de la } \\
\text { ciudad }\end{array}$} & $\begin{array}{l}\text { Menos de } \\
6 \mathrm{~km}\end{array}$ & 4 & \multirow{4}{*}{5} & 4 & \multirow{4}{*}{5} & 4 & & 4 & \multirow{4}{*}{5} \\
\hline & $\begin{array}{l}\text { Entre } 6 \mathrm{y} \\
7 \mathrm{~km}\end{array}$ & 3 & & 3 & & 3 & 60 & 3 & \\
\hline & $\begin{array}{l}\text { Entre } 7 \mathrm{y} \\
8 \mathrm{~km}\end{array}$ & 2 & & 2 & & 2 & & 2 & \\
\hline & Más de 8 km & 1 & & 1 & & 1 & & 1 & \\
\hline \multirow{4}{*}{$\begin{array}{l}\text { Estra- } \\
\text { tegias em- } \\
\text { pleadas }\end{array}$} & Abandono & 4 & \multirow{4}{*}{25} & 4 & \multirow{4}{*}{5} & 4 & & 4 & \multirow{4}{*}{50} \\
\hline & Supervivencia & 3 & & 3 & & 3 & 5 & 3 & \\
\hline & Acumulación & 2 & & 2 & & 2 & 3 & 2 & \\
\hline & Ninguna & 1 & & 1 & & 1 & & 1 & \\
\hline \multirow{4}{*}{$\begin{array}{l}\text { Expec- } \\
\text { tativas }\end{array}$} & No expresó & 4 & \multirow{4}{*}{5} & 4 & \multirow{4}{*}{25} & 4 & & 4 & \multirow{4}{*}{5} \\
\hline & Expandirse & 3 & & 3 & & 3 & & 3 & \\
\hline & $\begin{array}{l}\text { Mejorar } \\
\text { su calidad } \\
\text { de vida }\end{array}$ & 2 & & 2 & & 2 & 5 & 2 & \\
\hline & Permanecer & 1 & & 1 & & 1 & & 1 & \\
\hline
\end{tabular}




\begin{tabular}{|c|c|c|c|c|c|c|c|c|c|}
\hline \multirow{4}{*}{$\begin{array}{l}\text { Tipo de } \\
\text { anclaje } \\
\text { territorial }\end{array}$} & $\begin{array}{l}\text { Evalúa irse } \\
\text { del rururbano }\end{array}$ & 4 & \multirow{4}{*}{5} & 4 & \multirow{4}{*}{25} & 4 & \multirow{4}{*}{5} & 4 & \multirow{4}{*}{5} \\
\hline & $\begin{array}{l}\text { En proceso } \\
\text { de cons- } \\
\text { trucción de } \\
\text { anclaje }\end{array}$ & 3 & & 3 & & 3 & & 3 & \\
\hline & $\begin{array}{l}\text { Forzados } \\
\text { por razones } \\
\text { familiares o } \\
\text { laborales }\end{array}$ & 2 & & 2 & & 2 & & 2 & \\
\hline & $\begin{array}{l}\text { Enamorado } \\
\text { del lugar }\end{array}$ & 1 & & 1 & & 1 & & 1 & \\
\hline \multirow{4}{*}{$\begin{array}{l}\text { Califi- } \\
\text { cación } \\
\text { de los } \\
\text { vínculos } \\
\text { sociales }\end{array}$} & $\begin{array}{l}\text { No se vin- } \\
\text { culan con } \\
\text { sus vecinos }\end{array}$ & 4 & \multirow{4}{*}{5} & 4 & \multirow{4}{*}{25} & 4 & \multirow{4}{*}{5} & 4 & \multirow{4}{*}{5} \\
\hline & $\begin{array}{l}\text { Vinculación } \\
\text { mínima } \\
\text { (conocidos) }\end{array}$ & 3 & & 3 & & 3 & & 3 & \\
\hline & $\begin{array}{l}\text { Vínculos } \\
\text { por razones } \\
\text { laborales }\end{array}$ & 2 & & 2 & & 2 & & 2 & \\
\hline & $\begin{array}{l}\text { Vínculos de } \\
\text { coopera- } \\
\text { ción y ayuda } \\
\text { solidaria }\end{array}$ & 1 & & 1 & & 1 & & 1 & \\
\hline \multirow{4}{*}{$\begin{array}{l}\text { Tenen- } \\
\text { cia de la } \\
\text { tierra }\end{array}$} & Empleado & 4 & \multirow{4}{*}{5} & 4 & \multirow{4}{*}{5} & 4 & \multirow{4}{*}{10} & 4 & \multirow{4}{*}{10} \\
\hline & Arrendatario & 3 & & 3 & & 3 & & 3 & \\
\hline & $\begin{array}{l}\text { Propietario } \\
\text { de menos } \\
\text { de } 10 \text { años }\end{array}$ & 2 & & 2 & & 2 & & 2 & \\
\hline & $\begin{array}{l}\text { Propietario } \\
\text { de más de } \\
10 \text { años }\end{array}$ & 1 & & 1 & & 1 & & 1 & \\
\hline
\end{tabular}

Fuente: elaboración personal (2015)

Figura 2. Esquema metodológico

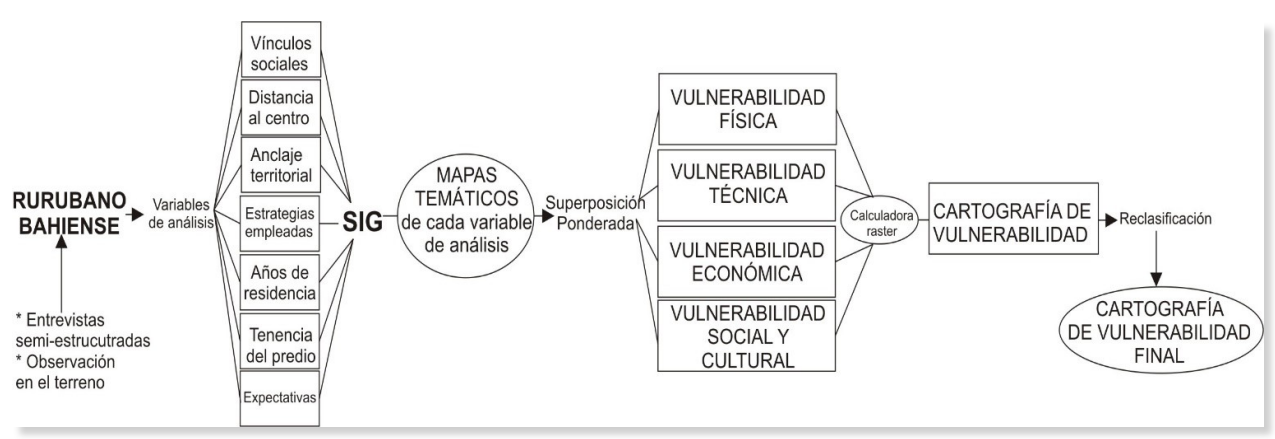

Fuente: elaboración personal (2019) 
VULNERABILIDAD: APORTES CONCEPTUALES PARA EL ESTUDIO DEL RURURBANO

La expansión urbana se percibe como un peligro para los residentes del rururbano -especialmente los relacionados a tareas agropecuarias intensivas, extensivas o extractivas- puesto que pone en riesgo su permanencia en el lugar, la conservación de sus propiedades o actividades y la continuidad del ritmo de vida propio de los ámbitos de borde, en especial, por el crecimiento de población del ámbito urbano que conlleva a un enfrentamiento de lógicas de habitar dispares e incompatibilidad en los usos del suelo.

En este marco, los conceptos de riesgo y vulnerabilidad resultan útiles para comprender la situación de constante mutabilidad y transformación del rururbano y la manera en cómo sus pobladores reaccionan, se adaptan y responden a las tensiones propias del área.

Existen diferentes perspectivas para definir riesgo, por un lado, puede considerarse como un conflicto de interacción entre la naturaleza y el accionar del hombre, así se pueden nombrar riesgos naturales y tecnológicos. Por otra parte, nociones más abarcativas entienden que todo evento, sea natural o social puede ocasionar riesgos, argumentando que "...se refiere a la posibilidad de que una contingencia (ocurrencia o presencia de un evento, característica o proceso) entrañe efectos adversos para la unidad de referencia..." (CELADE, 2002, p. 3).

Barrenechea, Gentile, González y Natenzon (2005, p. 180-181), aunque con una visión centrada en los riesgos naturales, establecen cuatro dimensiones del riesgo que pueden extrapolarse al estudio de la población del rururbano bahiense. La primera dimensión es la "peligrosidad", entendida como "... el potencial peligroso que tienen los fenómenos naturales, potencial inherente al fenómeno mismo, sea cual sea su grado de artificialidad"; la "vulnerabilidad", se relaciona con la capacidad disminuida de una población o de una persona para hacer frente, adaptarse y superar las consecuencias de un peligro; la "exposición”, utilizada para referirse a la distribución de lo que es potencialmente afectable, la población y los bienes materiales "expuestos" al fenómeno peligroso; y la "incertidumbre", relacionada con las limitaciones en el estado del "conocimiento técnico" y las indeterminaciones en cuanto a competencias institucionales y normas políticas.

Esta perspectiva se complementa con la de Wilches-Chaux (1993) quien desagrega el concepto de vulnerabilidad en múltiples facetas y menciona distintos tipos, de los cuales se mencionan solo los aplicados en el trabajo. Así establece la vulnerabilidad física, relacionada a la localización de una población en una zona de riesgo o a la ineficiencia de infraestructura física para absorber los riesgos; la económica, asocia$\mathrm{da}$ al capital/ingresos de un grupo humano para enfrentar situaciones de riesgo; la social, referida a la cohesión interna de una comunidad, incluye relaciones entre ellos e identificación, aspectos que colaboran en la manera de sobrellevar y superar una situación catastrófica; la técnica, relacionada al capital tecnológico que posee una población; la vulnerabilidad cultural, referida a las características distintivas de una sociedad, concepciones, costumbres, valores, que lleva a concebir algo desde una perspectiva diferente a otra sociedad.

Katzman (2005) y Pizarro (2001) en sus indagaciones sobre vulnerabilidad y pobreza en Latinoamérica proponen estudiar este concepto relacionándolo con los activos 
(físicos/materiales; humanos/habilidades y destrezas sociales) y las probabilidades de acceso a bienes, servicios y/o actividades que otorguen bienestar). En esta línea, otro aporte significativo lo realizan Anderson y Woodrow (citado por Pérez de Armiño, 1999) quienes analizan las vulnerabilidades y capacidades de una población a través de la especificación de tres aspectos: los activos físicos -recursos productivos, infraestructuras, condiciones de la vivienda, tecnología, entre otros-; los activos sociales -que incluyen las relaciones/redes sociales y organización comunitaria- y las emociones y actitudes -vinculadas con los aspectos subjetivos que llevan a enfrentar con mejor o peor predisposición una situación conflictiva-.

Méndez Lemus y Vieyra Medrano (2012) brindan la mirada sobre vulnerabilidad y adaptación en la periferia urbana. Los autores sostienen que la vulnerabilidad en estos escenarios se da por cambios externos, tales como transformaciones económicas, productivas, políticas -muchas de ellas vinculadas a procesos urbanos-; y por cambios internos, ligados a la capacidad adaptativa de cada familia campesina para adaptar y reorganizar sus sistemas agropecuarios. En este marco, y al reflexionar sobre las posibles respuestas ante un riesgo, Saurí Pujol menciona dos tipos de acción frente al peligro:

... la resistencia o la capacidad del sistema socio-natural de seguir su funcionamiento normal a pesar de haber sufrido una perturbación, y la resiliencia o la capacidad de recobrarse de las alteraciones inducidas por una perturbación que han afectado substancialmente el funcionamiento de este sistema. (2003, p. 22)

Del mismo modo, Stadel (2008-2009, p. 187) sintetiza estas dimensiones en la noción de "resistividad" entendida como "... la capacidad de un sistema para absorber, estabilizar y superar condiciones e incidentes adversos, adaptarse a nuevas situaciones o impactos y finalmente recobrar y surgir de manera eficaz de estas situaciones".

En este artículo se entiende que el rururbano bahiense actual tiene potencial y el riesgo de convertirse en urbano; de allí la importancia de focalizar el estudio en una de las dimensiones del riesgo, la vulnerabilidad de sus residentes -en especial de los más antiguos- para analizar su capacidad de respuesta puesto que son las decisiones de estos actores -consecuencia de los sentimientos hacia el lugar y la actividad que practica, así como el anclaje territorial vinculado a la pertenencia al lugar- y la puesta en marcha de sus estrategias de resistencia y resiliencia -relacionadas a sus activos materiales, afectivos y sociales, así como a sus destrezas y habilidades- las que determinarán la propensión al cambio y la velocidad con la que esto ocurra.

\section{EL RURURBANO BAHIENSE: HETEROGENEIDAD SOCIO-ESPACIAL}

El rururbano bahiense constituye un mosaico de escenarios variados, si bien predomina el paisaje rural con una ocupación dispersa, se pueden diferenciar paisajes propios de ámbitos fluviales, dominados por la actividad ladrillera, otros donde la ocupación es escasa, pero en expansión, o aquellos signados por la decadencia de la actividad rural intensiva (Figura 3). Entre los elementos naturales del área de estudio destacan el Arroyo Napostá y la vegetación asociada a este sistema fluvial, en el rururbano noreste; así como los relictos de bosquecillos de chañar y ejemplares de caldén en el rururbano noroeste. Los usos del suelo que se distinguen son los relacionados a tareas rurales intensivas -ya sea hortícola, avícola o cría de cerdos-, actividades recreativas y residencial disperso. 
Figura 3. Paisajes dominados a) por un elemento natural: el Arroyo Napostá y la vegetación asociada; b) por la actividad en hornos de ladrillo; c) por la ocupación en expansión y d) la actividad intensiva/extensiva en decadencia
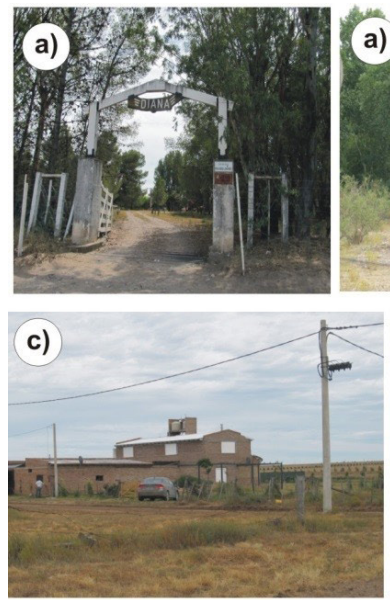
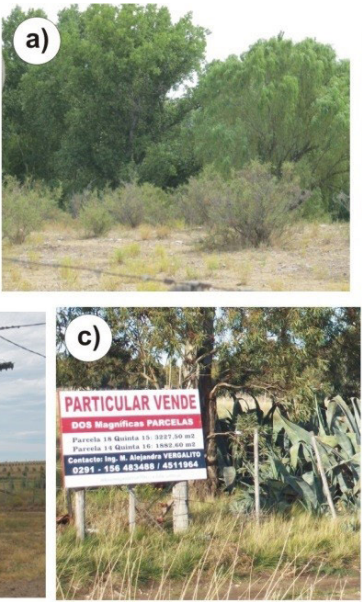
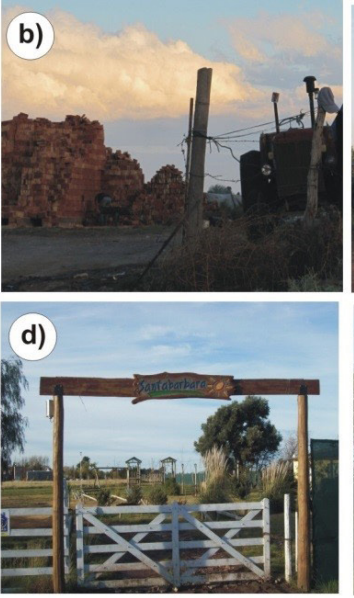
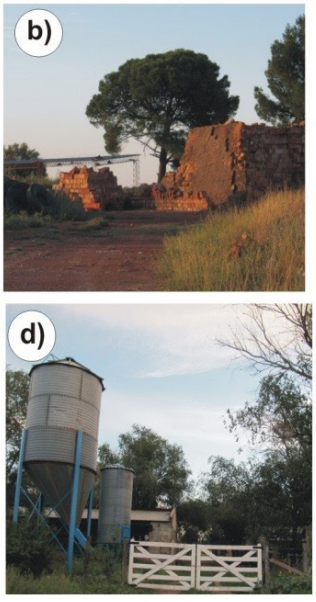

Fuente: fotografías tomadas por la autora (2014)

Teniendo en cuenta la observación y entrevistas realizadas, existen cuatro tipos de residentes: los dedicados a actividades rurales -subdivididos entre los que trabajan de manera extensiva y los abocados a tareas intensivas, ya sea horticultura, cría de aves, de porcinos, equinos o actividades extractivas-; los que son contratistas y prestan servicios rurales; los antiguos residentes ligados al ámbito rural en su juventud o que actualmente trabajan en campos más alejados del área de estudio y los nuevos habitantes quienes deciden asentarse en las afueras de la ciudad impulsados por la tranquilidad y el mayor contacto con la naturaleza que ofrece la periferia.

En el área de estudio las prácticas domésticas de los residentes dedicados a tareas extensivas o intensivas se conjugan con las laborales. La actividad rural es parte de la vida y de la historia familiar, es decir, trabajo, cotidianidad y espacio vivido se convierten en sinónimos que coinciden en el mismo lugar geográfico (Lindón, 2002b). Se evidencia, a través de las entrevistas, que existen fuertes lazos de pertenencia y arraigo aún en aquellos residentes que no son propietarios -especialmente los dedicados a la actividad rural extensiva o intensiva y los antiguos residentes del área- que a pesar de estar sometidos a presiones económicas y de expansión urbana, por lo general espontánea, no reconocen cuán vulnerable es 'su lugar'. Son espacios apropiados -desde lo material pero también desde los sentimientos y lo emocional- y defendidos por sus residentes porque son valuados y sentidos desde la pertenencia, el arraigo y el sentido de identidad (Escalera Reyes, 2013). En este contexto, prevalecen un sinnúmero de vínculos basados en la solidaridad, la amistad y la confianza dado que los vecinos se conocen y ayudan. Estos lazos se convierten en estrategias para enfrentar y superar las situaciones que perturban su estabilidad.

La mayoría de los entrevistados afirma tener una adaptación activa, resiliente, de resistencia ante las transformaciones de su vida cotidiana y socio-espaciales que experimentan. Cada habitante, entonces, procura valorizar sus recursos, aunque limitados en algunos casos, así como mantener su capacidad productiva, diversificando actividades, incorporando tecnología, entre otras intervenciones.

En este sentido, la estrategia -para permanecer en el rururbano- que sobresale es la transmisión de valores y amor por las labores rurales y la propiedad a hijos y nietos; luego se mencionan, la creatividad, una actitud alerta a los cambios y la imple- 
mentación de actividades extra prediales. Mientras que las estrategias que menos se nombran son: diversificar las actividades dentro de la propiedad; conservar las relaciones con otros productores rurales, recurrir a asesoramiento técnico y apostar por la educación de sus hijos; por último, se implementan estrategias tales como arrendar otra propiedad más alejada para continuar con parte de la actividad agropecuaria, presentar proyectos tendientes a la urbanización de sus propiedades y esperar que se valorice la propiedad y luego venderla.

\section{Presiones urbanas en El RURURBano bahIENSE DESDE LA MiRADA DE SUS RESIDENTES}

La gestión de la ciudad, planteada a través de distintos planes ordenadores en los últimos años, ha afectado el rururbano. En 2009 se impulsa el Plan de Desarrollo Urbano que establece nuevos criterios de zonificación e impulsa la compactación dentro del área urbana y en la periferia. El área de estudio queda incluida dentro de la faja residencial de baja densidad y posee las condiciones más apropiadas para recibir el asentamiento de nuevos habitantes (Municipalidad de Bahía Blanca, 2009). Por otra parte, en el año 2010 se aprueba el Plan Director del Periurbano Bahiense (Municipalidad de Bahía Blanca, 2011) que establece nuevos límites para el espacio urbano y el periurbano (dentro del cual se encuentra el área de estudio) y delimita áreas propicias para urbanizar introduciendo, de este modo, una mayor presión en este espacio de borde ante la llegada de planes urbanizadores. Si bien, en la actualidad, estos proyectos de expansión de Bahía Blanca se encuentran detenidos -según informaron en la Oficina de Planeamiento y de Catastro de la Municipalidad de Bahía Blanca- existen progresos en cuanto a la demarcación de calles internas de nuevos barrios y provisión de servicios.

El trabajo en el terreno permitió corroborar los efectos de lo antes mencionado, a través de las incipientes construcciones en el área, la incorporación de loteos sumado a una considerada cantidad de terrenos en venta, en especial en el rururbano norte y en zonas lindantes a la Ruta Nacional No 3 (rururbano norte y noroeste). Asimismo, las entrevistas dan cuenta de la manera en que cada habitante vivencia estas transformaciones y son esclarecedoras acerca de los principales cambios percibidos en el paisaje, en su actividad y vida cotidiana, así como de los sentimientos que esta situación les genera. Una síntesis de sus expresiones se presenta en la Figura 4.

Figura 4. Cambios percibidos y sentimientos que genera la expansión de la ciudad sobre el rururbano de sus pobladores más antiguos

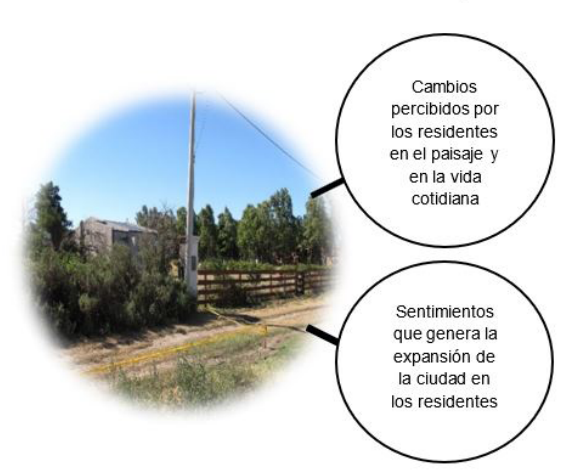

- Aumento de la población del área.

- Construcción de viviendas y barrios

- Aumento de los loteos.

Provisión de servicios en el área.

- Venta de terrenos.

- Aumento en los ruidos, al aumentar el tránsito vehicular.

- Nuevos proyectos inmobiliarios.

- Pérdida de la tranquilidad.

- Inseguridad por el aumento en los robos de sus viviendas y del

ganado que algunos poseen.

- Miedo.

- Dolor y angustia

Sentimiento de invasión de su lugar.

Incompatibilidad en las formas de habitar un espacio vivido.

- Inseguridad laboral.

- Resignación

- Agrado

- Disconformidad por la pérdida de la tranquilidad.

Fuente: elaboración personal con base en entrevistas a residentes del rururbano bahiense 
Del mismo modo, resulta enriquecedor rescatar algunas frases representativas, a manera de testimonio y complemento de la Figura 4. En este marco, algunos comentan:

Está cambiando el lugar porque está llegando la gente... cuando yo llegué acá estaba tipo campo... el vecino más cercano venía de vez en cuando ... yo estaba como sola... y ahora están llegando y es como que me incomoda... porque ya escucho las voces de uno... uno se hace un poco huraño... y aparte la paz... (Gr., propietaria en el rururbano norte desde 1992, entrevista realizada en 2013).

La zona se vuelve cada vez más urbana, porque hay más barrios, hay proyectos de otras personas o de propietarios vecinos, ha cambiado, antes era mucho más campo... (Lu., propietaria de un campo en el rururbano noroeste, entrevista realizada en 2015).

...el acercamiento de la ciudad conlleva ciertas características... un ejemplo... acá cuando se junta agua, vienen flamencos rosados, garzas moradas... este año los teros no criaron pichones... porque pasan con los cuatri para ver el barrio nuevo... viene mucha gente de poder adquisitivo... ha llegado un poco la incivilización... ( $V$., propietario en el noroeste del rururbano bahiense y prestador de servicios de construcción, entrevista realizada en 2014 ).

La expansión urbana es percibida por todos los entrevistados como un peligro asociado, en algunos casos, a la inseguridad de sus bienes (vivienda, animales, equipamiento de trabajo) debido a los robos que comienzan a ser frecuentes, en otros, a la mayor exposición a alimañas y otros animales -ratas, perros abandonados, por mencionar algunos-, a la pérdida de la tranquilidad puesto que se genera una mayor dinámica en las cercanías de los campos y a la posibilidad de perder sus fuentes de trabajo o tener que vender sus propiedades. En este sentido varios opinan sobre los sentimientos que les genera el avance de la ciudad:

El progreso no lo podés parar, se va perdiendo la seguridad, te pispean, te observan. Cerca de mi casa han robado un montón de veces... (C., agrimensor residente en el rururbano hace más de 25 años, entrevista realizada en 2014$)$.

(El hecho de que la ciudad este extendida para este lado) ...me genera miedo... Me duele que la ciudad se venga... (Pr., prestador de servicios rurales, entrevista realizada en 2013).

El grupo de residentes que arrienda o son empleados de las distintas actividades intensivas en el borde urbano también manifiesta la impresión sobre el crecimiento de la ciudad en sus espacios vividos, pero con una actitud de resignación o temor:

Tengo temor de quedarme sin trabajo, porque al venirse la ciudad, se tienen que ir los hornos, si había hornos hoy quedan... cuando la ciudad avance va a quedar mucha gente dando vueltas. (R., empleado de un horno de ladrillo en la periferia norte de Bahía Blanca, entrevista realizada en 2013).

Entre los entrevistados, solo una horticultora expresó una percepción positiva y comentó:

(El hecho de que la ciudad está extendida para este lado me genera) Nada... son dueños los que están construyendo... no hay usurpación... lo que yo hago es todo orgánico... si fumigara tendría problemas porque afecta a los vecinos por el olor y toda esas cosas... pero como no lo hago... veo la posibilidad de seguir creciendo, si no cambiar el rubro y hacer todo bajo cubierta... (S., horticultora en el rururbano noroeste de la ciudad de Bahía Blanca, entrevista realizada en 2014).

Es dable mencionar que la expansión de la ciudad provoca incertidumbre en la mayoría de los residentes del rururbano, en especial, aquellos dedicados a tareas agropecuarias, tanto por la posible eliminación de suelo rural, la eventualidad de perder la fuente de trabajo como cambiar el ritmo de vida, con la consecuente desaparición de la tranquilidad del área. 
VULNERABILIDAD EN EL ÁREA DE ESTUDIO: UN MODO DE VIDA AMENAZADO POR LA EXPANSIÓN URBANA

La aplicación del procedimiento detallado en la metodología permitió obtener la cartografía de los distintos tipos de vulnerabilidad (Figura 2 y Tabla 2). La observación de la cartografía de vulnerabilidad económica (Figura 5a) sumado a los aportes de las entrevistas permite corroborar que los entrevistados con alta vulnerabilidad -situados, en especial, en el este y noroeste del rururbano- emplean estrategias de sobrevivencia y reflexionan sobre la posibilidad de irse de la propiedad debido al tipo de actividad intensiva o extensiva a la que se dedican. En este grupo, se encuentra la mayoría de los pobladores que no son propietarios y como consecuencia son más vulnerables a los cambios económicos. En contraposición, aquellos con vulnerabilidad media -distribuidos, en general, en el sector norte y noreste- presentan similares características que los anteriores, pero no acceden a irse del lugar, es decir, sus expectativas están basadas en la permanencia en el borde rural-urbano, cuestión sobre la que se basa la diferencia en los resultados. Incluye ex-productores rurales, la totalidad de los prestadores de servicios al campo entrevistados y algunos habitantes dedicados a actividades del agro intensivas y extensivas. En el grupo de baja vulnerabilidad económica, localizados al norte y noreste, se concentran los nuevos pobladores, ocupados en tareas urbanas que no ponen en marcha estrategias de resistencia o adaptación a la urbanización.

En relación a la vulnerabilidad física (Figura 5b) el grupo que presenta una alta vulnerabilidad se encuentra a menos de $7 \mathrm{~km}$ del centro de la ciudad en el noroeste del rururbano; los entrevistados con vulnerabilidad media se localiza entre 7 y $8 \mathrm{~km}$ de la plaza Rivadavia distribuidos en los distintos puntos del espacio bajo estudio; mientras que los que poseen vulnerabilidad baja están ubicados en el norte por situarse a más de 8 kilómetros.

En la Figura 6a quedan plasmados aquellos que son más vulnerables desde lo social y cultural. En este sentido, los entrevistados en proceso de formación de anclaje, forzados por razones laborales/familiares o evaluando la posibilidad de irse del rururbano poseen alta vulnerabilidad. Este grupo se emplaza en el este y noroeste del sector bajo estudio. En contraposición los enamorados del lugar donde habitan, con expectativas de permanencia y vínculos basados en la solidaridad y amistad que da cuenta de una construcción de lazos sociales en el tiempo, presentan una baja vulnerabilidad. Son, en general, prestadores de servicios rurales y antiguos residentes del borde norte y noreste, cuyas actividades pueden conservarse en caso de avanzar la urbanización; aunque también incluye un productor rural.

Los consultados con una vulnerabilidad media están concentrados, en particular, en el norte y noroeste de esta franja; abarcan residentes dedicados a tareas intensivas y extensivas, con fuerte anclaje territorial, expectativas de permanencia y quienes manifiestan establecer vínculos entre vecinos por cuestiones laborales o simplemente ser 'conocidos'.

Las propiedades con mayor vulnerabilidad técnica (Figura 6b) comprenden pobladores que no solo emplean estrategias de sobrevivencia, sino que evalúan dejar el rururbano aun siendo propietarios o son empleados en una actividad que tiende a desaparecer con la llegada de la urbanización. Los mismos se sitúan, en particular, hacia el este y noroeste. En una posición opuesta, los entrevistados, localizados en el área norte, pre- 
sentan una vulnerabilidad técnica baja y son nuevos residentes del borde que no ponen en marcha estrategias de rechazo a la urbanización, al contrario, observan con agrado la llegada de nuevos pobladores y la consecuente extensión de los servicios de gas, luz, cloacas, agua potable al lugar.

Figura 5. Vulnerabilidad económica (a) y física (b) en el área de estudio

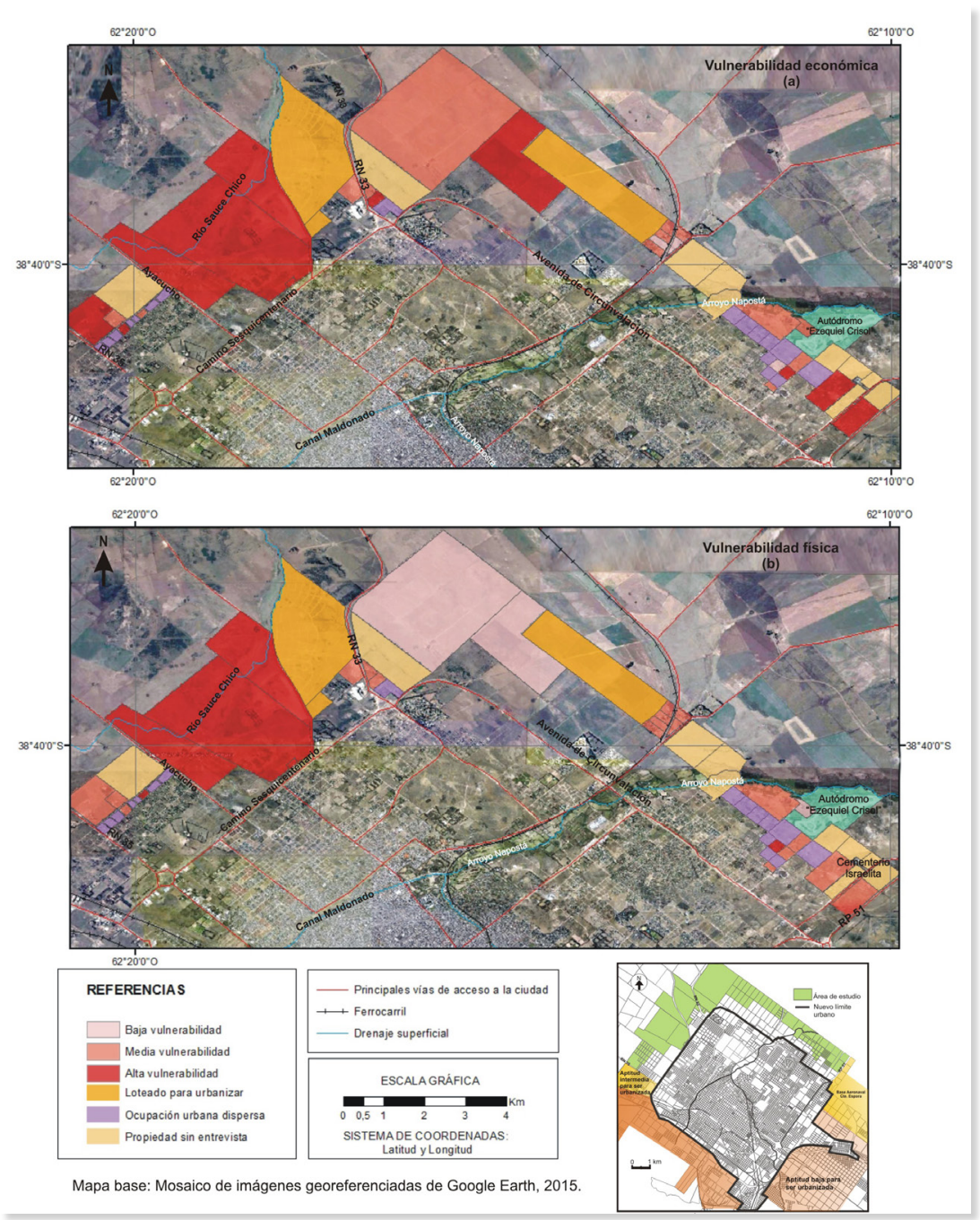

Fuente: elaboración personal con base en trabajo de campo y aplicación de procedimientos con SIG, 2016 
Figura 6. Vulnerabilidad social y cultural (a) y vulnerabilidad técnica (b) en el área de estudio
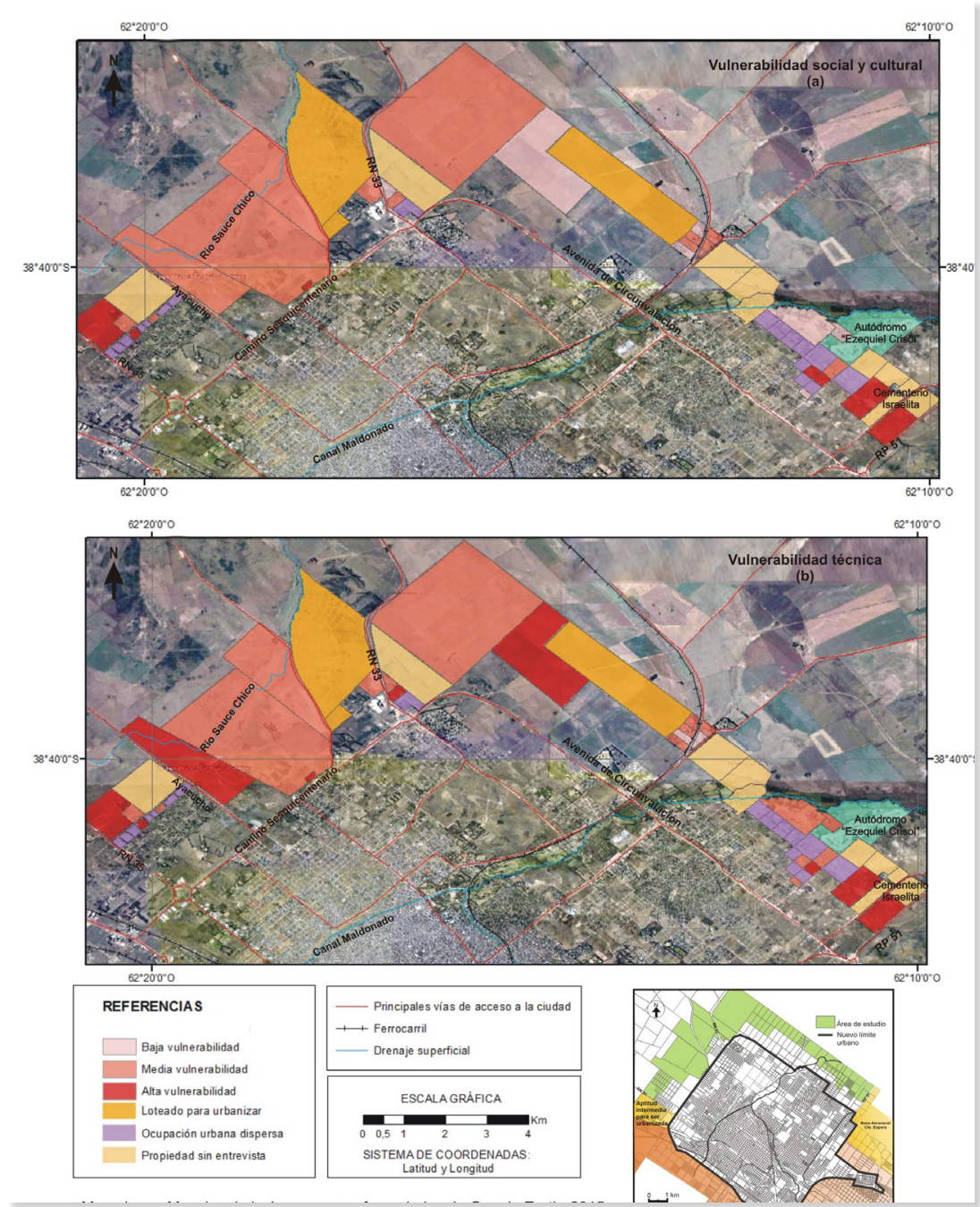

Fuente: elaboración personal con base en trabajo de campo y aplicación de procedimientos con SIG, 2016

Mientras que aquellos residentes del área noroeste, norte y noreste, que emplean estrategias de sobrevivencia, pero son propietarios, con un fuerte anclaje al lugar, una red de vínculos sociales afianzada y perdurable y, como consecuencia, sin deseos de acceder a irse de la propiedad; o los que con mejores recursos económicos emplean estrategias de acumulación y son propietarios, aunque su red de vínculos es débil y solo por cuestiones laborales, quedan comprendidos en la categoría de vulnerabilidad técnica media.

La correlación de cada vulnerabilidad individual, permite obtener la cartografía de vulnerabilidad síntesis (Figura 7). Para interpretar los resultados se utiliza la matriz de vulnerabilidades y capacidades que permite analizar las características de cada grupo (Anderson y Woodrow citado por Pérez de Armiño, 1999) (Tabla 3).

En este contexto, los entrevistados que pertenecen al grupo de los menos vulnerables presentan una capacidad mayor para absorber, estabilizar y superar condiciones e incidentes adversos, adaptarse a nuevas situaciones o impactos y finalmente recobrar y surgir de manera eficaz de estas situaciones (Stadel, 2008-2009); lo componen, en general, pobladores cuya tarea puede continuar en caso de avanzar la urbanización o los que prac- 
ticando alguna actividad intensiva o extensiva presentan una vulnerabilidad física baja y un fuerte anclaje al lugar que los impulsa a resistir poniendo en funcionamiento distintas habilidades y destrezas. En tanto que aquellos cuya capacidad de respuesta y adaptación está disminuida para poder superar la crisis que genera la exposición a un peligro son más vulnerables a la expansión de la ciudad y a ser absorbidos por la misma. Este conjunto de pobladores incluye los trabajadores en hornos de ladrillo, los propietarios que evalúan irse del rururbano por la incompatibilidad de sus tareas con el uso residencial, las pérdidas o molestias que ocasionan sus prácticas a los nuevos residentes sumado a una alta vulnerabilidad económica. Además, gran parte de los residentes de este grupo se califica con un anclaje forzado por razones laborales -es decir, no necesariamente elige el rururbano para habitar- y cuya red de vínculos se relaciona a cuestiones de trabajo.

En síntesis, los residentes con mayor vulnerabilidad se emplazan en el rururbano noroeste y hacia el este; mientras que los de menor vulnerabilidad quedan localizados hacia el norte y noreste. En este marco, se reflexiona sobre el crecimiento histórico de la ciudad que se dio, en particular, hacia el sector norte y noreste. En la actualidad estas áreas (norte y noreste) coinciden con los grupos menos vulnerables, cuestión que podría afectar la continuidad de esta tendencia, puesto que la mayoría de los consultados tienen baja disposición a los cambios; situación que lleva a plantear un interrogante ¿influirá esta posición mayoritaria en posibles avances de la urbe?

Figura 7. Vulnerabilidad síntesis en el área de estudio

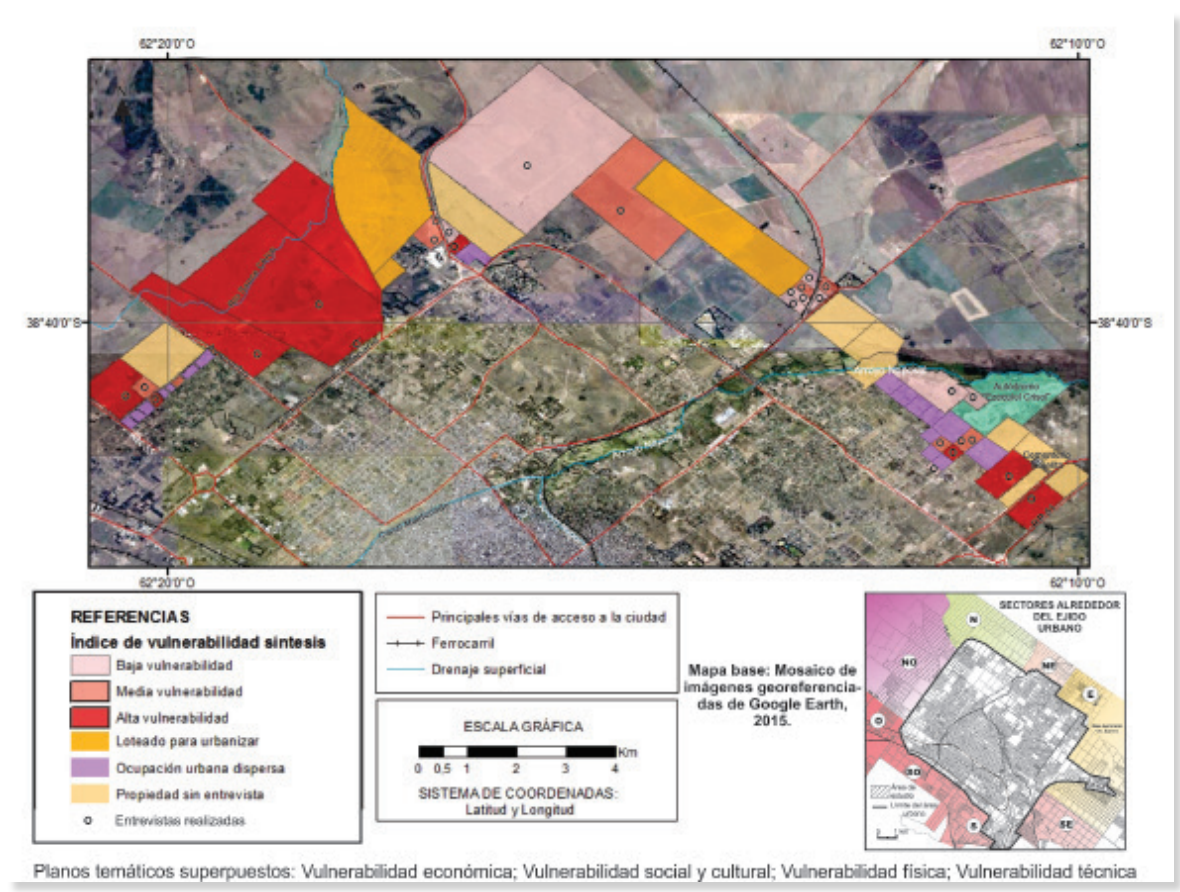

Fuente: elaboración personal con base en trabajo en el terreno y aplicación de procedimientos con SIG, 2016 
Tabla 3. Vulnerabilidad síntesis: análisis de los residentes del área de estudio

\begin{tabular}{|c|c|c|c|c|c|c|}
\hline \multirow[t]{2}{*}{$\begin{array}{l}\text { Matriz de } \\
\text { análisis }\end{array}$} & \multicolumn{2}{|c|}{$\begin{array}{l}\text { Residentes con vul- } \\
\text { nerabilidad baja }\end{array}$} & \multicolumn{2}{|c|}{$\begin{array}{l}\text { Residentes con vul- } \\
\text { nerabilidad media }\end{array}$} & \multicolumn{2}{|c|}{$\begin{array}{c}\text { Residentes con vul- } \\
\text { nerabilidad alta }\end{array}$} \\
\hline & $\begin{array}{l}\text { Vulnera- } \\
\text { bilidades }\end{array}$ & Capacidades & $\begin{array}{l}\text { Vulnerabi- } \\
\text { lidades }\end{array}$ & Capacidades & $\begin{array}{l}\text { Vulnera- } \\
\text { bilidades }\end{array}$ & Capacidades \\
\hline $\begin{array}{l}\text { Físicas/ } \\
\text { materiales } \\
\text { ¿Qué } \\
\text { recursos } \\
\text { productivos, } \\
\text { conocimien- } \\
\text { tos y riesgos } \\
\text { existen? }\end{array}$ & & $\begin{array}{l}\text { Conoci- } \\
\text { miento de } \\
\text { las tareas a } \\
\text { las que se } \\
\text { dedican, la } \\
\text { mayoría en } \\
\text { la ciudad, } \\
\text { otros son } \\
\text { prestadores } \\
\text { de servicios } \\
\text { rurales y } \\
\text { también } \\
\text { existen } \\
\text { unos pocos } \\
\text { dedicados a } \\
\text { tareas con } \\
\text { equinos o } \\
\text { ganaderas. } \\
\text { Todos son } \\
\text { propietarios. } \\
\text { Habitan los } \\
\text { predios más } \\
\text { alejados del } \\
\text { centro de } \\
\text { la ciudad. } \\
\text { Poseen } \\
\text { actividades } \\
\text { que podrían } \\
\text { continuar } \\
\text { en el caso } \\
\text { de poblarse } \\
\text { más la zona, } \\
\text { excepto uno. } \\
\text { Implemen- } \\
\text { tan estrate- } \\
\text { gias de so- } \\
\text { brevivencia y } \\
\text { de acumula- } \\
\text { ción; aunque } \\
\text { predominan } \\
\text { las primeras. }\end{array}$ & $\begin{array}{l}\text { Comprenden } \\
\text { los predios } \\
\text { menos } \\
\text { alejados del } \\
\text { centro de } \\
\text { la ciudad, } \\
\text { excepto uno } \\
\text { de ellos. } \\
\text { La mayoría } \\
\text { practica } \\
\text { activida- } \\
\text { des que, } \\
\text { en algunos } \\
\text { casos, están } \\
\text { en riesgo de } \\
\text { continuar si } \\
\text { se poblara } \\
\text { más la zona. } \\
\text { Algunos } \\
\text { dependen de } \\
\text { las decisio- } \\
\text { nes de los } \\
\text { propietarios } \\
\text { del predio en } \\
\text { el que viven } \\
\text { o trabajan. }\end{array}$ & $\begin{array}{l}\text { Conoci- } \\
\text { miento de } \\
\text { las tareas a } \\
\text { las que se } \\
\text { dedican. } \\
\text { Incluye } \\
\text { residentes } \\
\text { dedicados a } \\
\text { actividades } \\
\text { intensivas y } \\
\text { extensivas, } \\
\text { dos nuevos } \\
\text { residentes y } \\
\text { un presta- } \\
\text { dor rural. } \\
\text { La mayoría } \\
\text { son pro- } \\
\text { pietarios. } \\
\text { Algunos } \\
\text { cuentan con } \\
\text { tecnología, } \\
\text { aunque } \\
\text { no la más } \\
\text { moderna } \\
\text { para realizar } \\
\text { sus tareas. } \\
\text { Imple- } \\
\text { mentan } \\
\text { estrategias } \\
\text { de sobrevi- } \\
\text { vencia, pero } \\
\text { también } \\
\text { algunas } \\
\text { de acumu- } \\
\text { lación. }\end{array}$ & $\begin{array}{l}\text { Son em- } \\
\text { pleados } \\
\text { o arren- } \\
\text { datarios, } \\
\text { solo uno es } \\
\text { propietario } \\
\text { y tiene su } \\
\text { propiedad } \\
\text { en venta. } \\
\text { Compren- } \\
\text { den los pre- } \\
\text { dios menos } \\
\text { alejados del } \\
\text { centro de } \\
\text { la ciudad. } \\
\text { Practican } \\
\text { actividades } \\
\text { que están } \\
\text { en riesgo de } \\
\text { continuar } \\
\text { en el caso } \\
\text { de poblar- } \\
\text { se más la } \\
\text { zona. } \\
\text { Predios de } \\
\text { escasas } \\
\text { dimensio- } \\
\text { nes, con } \\
\text { tecnología } \\
\text { básica. } \\
\text { Dependen } \\
\text { de las de- } \\
\text { cisiones de } \\
\text { los propie- } \\
\text { tarios del } \\
\text { predio en } \\
\text { que viven o } \\
\text { trabajan. } \\
\text { Implemen- } \\
\text { tan estrate- } \\
\text { gias de so- } \\
\text { brevivencia, } \\
\text { tecnologíasas } \\
\text { limas. }\end{array}$ & $\begin{array}{l}\text { Conocimien- } \\
\text { to de las } \\
\text { tareas a las } \\
\text { que se dedi- } \\
\text { can entre las } \\
\text { que están la } \\
\text { producción } \\
\text { de ladrillos } \\
\text { y la horti- } \\
\text { cultura. } \\
\text { Incluye } \\
\text { residentes } \\
\text { dedicados a } \\
\text { actividades } \\
\text { intensivas. } \\
\text { Dos de ellos } \\
\text { emplean } \\
\text { estrategias } \\
\text { creativas } \\
\text { para ampliar } \\
\text { y diversificar } \\
\text { su pro- } \\
\text { ducción. }\end{array}$ \\
\hline
\end{tabular}




\begin{tabular}{|c|c|c|c|c|c|c|}
\hline $\begin{array}{l}\text { Sociales/or- } \\
\text { ga-nización } \\
\text { ¿Cuáles } \\
\text { son las } \\
\text { relaciones } \\
\text { y organiza- } \\
\text { ción entre } \\
\text { personas? }\end{array}$ & $\begin{array}{l}\text { Algunos de } \\
\text { ellos recién } \\
\text { comienzan } \\
\text { a estable- } \\
\text { cer lazos } \\
\text { de amistad } \\
\text { con los } \\
\text { vecinos } \\
\text { del lugar } \\
\text { por su } \\
\text { condición } \\
\text { de nuevos } \\
\text { residentes. }\end{array}$ & $\begin{array}{l}\text { En la ma- } \\
\text { yoría de } \\
\text { los casos } \\
\text { poseen una } \\
\text { red de víncu- } \\
\text { los sociales } \\
\text { fuerte, ba- } \\
\text { sadas en la } \\
\text { ayuda mutua } \\
\text { y la coope- } \\
\text { ración entre } \\
\text { vecinos. }\end{array}$ & & $\begin{array}{l}\text { En la ma- } \\
\text { yoría de } \\
\text { los casos } \\
\text { poseen una } \\
\text { red de víncu- } \\
\text { los sociales } \\
\text { fuerte, ba- } \\
\text { sadas en la } \\
\text { ayuda mutua } \\
\text { y la coope- } \\
\text { ración entre } \\
\text { vecinos. }\end{array}$ & $\begin{array}{l}\text { Poseen, en } \\
\text { general, } \\
\text { una red de } \\
\text { vínculos } \\
\text { sociales } \\
\text { débil. Esta- } \\
\text { blecen lazos } \\
\text { de tipo } \\
\text { laboral. }\end{array}$ & $\begin{array}{l}\text { Solo uno } \\
\text { establece re- } \\
\text { laciones con } \\
\text { organismos } \\
\text { relacionados } \\
\text { a tecnología } \\
\text { agropecuaria } \\
\text { y otro mani- } \\
\text { festó perte- } \\
\text { necer a una } \\
\text { agrupación } \\
\text { de producto- } \\
\text { res agrope- } \\
\text { cuarios. }\end{array}$ \\
\hline $\begin{array}{l}\text { De moti- } \\
\text { vaciones/ } \\
\text { actitudes } \\
\text { ¿Cómo ve } \\
\text { la comu- } \\
\text { nidad su } \\
\text { capacidad } \\
\text { para crear } \\
\text { el cambio? }\end{array}$ & $\begin{array}{l}\text { Observan } \\
\text { con resig- } \\
\text { nación, en } \\
\text { parte, y con } \\
\text { rechazo, } \\
\text { por otra, la } \\
\text { llegada de } \\
\text { la urbani- } \\
\text { zación. }\end{array}$ & $\begin{array}{l}\text { Topofilia } \\
\text { intensa } \\
\text {-ligada a } \\
\text { experiencias } \\
\text { placenteras } \\
\text { que afianzan } \\
\text { el sentido } \\
\text { de perte- } \\
\text { nencia- (Lin- } \\
\text { dón, 2005), } \\
\text { basada en } \\
\text { el amor al } \\
\text { lugary a las } \\
\text { condiciones } \\
\text { naturales } \\
\text { que allí se } \\
\text { encuentran. } \\
\text { Desean } \\
\text { permanecer } \\
\text { en el lugar. } \\
\text { Valoran el } \\
\text { lugar donde } \\
\text { viven al } \\
\text { punto de } \\
\text { considerarlo } \\
\text { esencial para } \\
\text { su vida. }\end{array}$ & $\begin{array}{l}\text { Algunos } \\
\text { poseen un } \\
\text { tipo de an- } \\
\text { claje forzado } \\
\text { por razones } \\
\text { laborales o } \\
\text { familiares; lo } \\
\text { que impli- } \\
\text { ca que no } \\
\text { necesaria- } \\
\text { mente eligen } \\
\text { el lugar } \\
\text { para vivir. }\end{array}$ & $\begin{array}{l}\text { Se califi- } \\
\text { can como } \\
\text { enamorados } \\
\text { del lugar; } \\
\text { desean per- } \\
\text { manecer en } \\
\text { él y manifies- } \\
\text { tan amor a } \\
\text { la tarea que } \\
\text { realizan, ge- } \\
\text { neralmente } \\
\text { por haberlo } \\
\text { hecho toda } \\
\text { su vida y } \\
\text { heredado de } \\
\text { sus padres. }\end{array}$ & $\begin{array}{l}\text { Tipo de } \\
\text { anclaje } \\
\text { forzado por } \\
\text { razones la- } \\
\text { borales; lo } \\
\text { que implica } \\
\text { que no ne- } \\
\text { cesariamen- } \\
\text { te eligen } \\
\text { el lugar } \\
\text { para vivir. }\end{array}$ & $\begin{array}{l}\text { Desean per- } \\
\text { manecer en } \\
\text { el lugar por- } \\
\text { que allí está } \\
\text { su fuente } \\
\text { de trabajo. } \\
\text { Amor a la } \\
\text { tarea que } \\
\text { realizan, ge- } \\
\text { neralmente } \\
\text { por haberlo } \\
\text { hecho toda } \\
\text { su vida y } \\
\text { heredado, } \\
\text { en algunos } \\
\text { casos de } \\
\text { sus padres. }\end{array}$ \\
\hline
\end{tabular}

Fuente: elaboración personal con base en entrevistas realizadas entre los años 2010-2015 y procesamiento de datos con SIG

\section{REFLEXIONES FINALES}

A manera de cierre, el trabajo no solo recupera las vivencias y percepciones del grupo de pobladores más antiguos del área sino que destaca que el amor al lugar se convierte en una fortaleza para los habitantes de estos bordes, la clave que sustenta las acciones para enfrentar presiones -muchas veces más fuertes de lo que pueden sobrellevar- que, en conjunto con los lazos solidarios, de amistad y confianza con otros vecinos dedicados a la misma actividad y las expectativas futuras relacionadas a la continuidad en la 
propiedad son factores de 'resistividad' y de resiliencia frente a los cambios. El análisis de la cartografía síntesis de vulnerabilidad permite corroborar que este sentido de identidad territorial (Moraga López, 2011) fundado en los activos intangibles -sentimientos, pertenencia y significados hacia sus espacios vividos- diferencia e incide en la capacidad de los residentes para movilizar recursos y aprovechar oportunidades que, en consecuencia, los hacen más o menos vulnerables frente a la situación objeto de estudio.

En este contexto, y como parte del proceso de reflexión sobre el tema, surgen nuevas incógnitas tales como ¿qué puede pasar si se concreta la venta de los sectores más vulnerables?, ¿cómo procederán los que no quieren irse ante la instalación de nuevos barrios al lado de sus propiedades?, ¿se contemplarán desde los organismos de planificación urbana los intereses de los antiguos pobladores de este espacio?; todas ellas abren nuevas líneas de análisis y posibilidades de ampliar el estudio, considerando otros indicadores y aspectos.

Por otra parte, la propuesta metodológica del trabajo basada en la combinación de técnicas y la complementación de los resultados demuestra los beneficios de esta perspectiva para abordar el estudio de un espacio complejo y cambiante como es el rururbano bahiense, en particular, como otros ámbitos transicionales.

En este sentido, queda demostrado el valor del trabajo de campo, la aplicación de entrevistas semiestructuradas y la observación como medios para recuperar las miradas de los propios pobladores y reflexionar teniendo en cuenta sus intereses y situación; y el aporte de un SIG, que complementa el análisis cualitativo y permite diseñar bases de datos espaciales, superponer y ponderar distintas capas de información para obtener cartografía temática y de síntesis como la de vulnerabilidad.

\section{REFERENCIAS}

Arango Escobar, G. (2008). Salvemos el espacio rururbano colombiano. Cuadernos de Vivienda y Urbanismo, 1(2), 394-409. Recuperado de https://revistas.javeriana.edu. co/index.php/cvyu/article/view/5499 (consulta septiembre de 2017).

Avalle, G. (2009). Clases y territorio: construcción de subjetividades en los movimientos sociales Avá. Revista de Antropología, (14), 1-19.

Ávila Sánchez, H. (2009). Periurbanización y espacios rurales en la periferia de las ciudades. Estudios Agrarios, (41), 93-123. Recuperado de http://www.pa.gob.mx/publica/ rev_41/ANALISIS/7\%20HECTOR\%20AVILA.pdf (consulta septiembre de 2016).

Barrenechea, J.; Gentile, E.; González, S. y Natenzon, C. (2005). Una propuesta metodológica para el estudio de la vulnerabilidad social en el marco de la teoría social del riesgo (pp. 179-196). En S. Lago Martínez, G. Gómez Rojas y M. Mauro (Coords.) En torno a las metodologías: abordajes cualitativos y cuantitativos. Buenos Aires: Proa XXI.

Barros, C. (1997). Lo rural y lo periurbano. Consideraciones acerca de la organización espacial en la cuenca de abasto de lácteos a Buenos Aires. VI Encuentro de Geógrafos de América Latina. Buenos Aires: EGAL.

Barros, C. (1999). De lo rural a rururbano: transformaciones territoriales y construcción de lugares al sudoeste del área metropolitana de Buenos Aires. Scripta Nova, (45). Recuperado de http://www.ub.es/geocrit/sn-45-52.htm (consulta diciembre de 2017). Barros, C. (2000). Reflexiones sobre la relación entre lugar y comunidad. Documents d'Anàlisi Geográfica, (37), 81-94. Recuperado de https://ddd.uab.cat/pub/da- 
g/02121573n37/02121573n37p81.pdf (consulta junio de 2016).

Barsky, A. (2005). El periurbano productivo, un espacio en constante transformación. Introducción al estado del debate, con referencias al caso de Buenos Aires. Scripta Nova, IX(194). Recuperado de http://www.ub.es /geocrit /sn/sn-194-36.htm (consulta marzo de 2013).

Bozzano, H. (2000). Territorios pensados, imaginados y reales. Buenos Aires: Espacio.

Cañon, S. (2014). El anclaje territorial y la construcción del discurso para la recuperación del yacón en Bárcena/Chorrillos, Quebrada de Humahuaca. IX Jornadas de Estudios Sociales de la Economía. Recuperado de http://www.idaes.edu.ar/pdf_papeles/Ca\%C3\%B1\%C3\%B3n,\%20Sebasti\%C3\%A1n_El\%20anclaje\%20territorial\%20y\%20la\%20 construcci\%C3\%B3n\%20del\%20discurso\%20para\%20la\%20recuperaci\%C3\%B3n\%20 del\%20yac\%C3\%B3n\%20en\%20B\%C3\%A1rcenaChorrill.pdf (consulta enero de 2015).

Cardozo, M.M. (2018). Desequilibrios territoriales en el área de expansión urbana. Vulnerabilidad y configuración morfológica en el sector norte de Santa Fé. Geograficando, 14(2). Recuperado de https://ri.conicet.gov.ar/bitstream/handle/11336/83008/CONICET_Digital_Nro.4ec415e7-c23c-42f4-8c22-b2fc6832aaed_A.pdf?sequence=2\&isAllowed=y (consulta julio de 2020).

Centro Latinoamericano y Caribeño de Demografía CELADE (2002). Vulnerabilidad socio demográfica: viejos y nuevos riesgos para comunidades, hogares y personas. Brasillia: Comisión Económica para América Latina y el Caribe, de las Naciones Unidas. Recuperado de https://repositorio.cepal.org/bitstream/handle/11362/13053/S2002600_es.pdf?sequence $=1$ (consulta marzo de 2013).

De Mattos, C. (1999). Santiago de Chile, globalización y expansión metropolitana: lo que existía sigue existiendo. Eure, 25(76). Recuperado de http://www.eure.cl/index. php/eure/article/view/1217 (consulta agosto del 2009).

Di Meo, G. (1999). Géographies tranquilles du quotidien. Une analyse de la contribution des sciences sociales et de la géographie à l'étude des pratiques spatiales. Cahiers de géographie du Québec, 43(118). DOI https://doi.org/10.7202/022788ar

Escalera Reyes, J. (2013). Amor a la tierra. Identidades colectivas y resiliencia de los socioecosistemas (pp. 333-378). En E. Ruiz Ballesteros y J.L. Solana Ruiz (Coords.) Complejidad y ciencias sociales. España: Universidad Internacional de Andalucía. Recuperado de http://www.alternativamijena.com/wp-content/uploads/2014/03/Amor-a-la-tierra-Javier-Escalera-.pdf (consulta abril de 2014).

ESRI (1995-2012). Tutorial de Spatial Analyst. California: Environmental Systems Research Institute. Recuperado de http://help.arcgis.com/es/arcgisdesktop/10.0/pdf/tutorial_ spatial_analyst.pdf. 56 pp. (consulta septiembre de 2015 a marzo de 2016).

Feito, M.C. (2018). Problemas y desafíos del Periurbano de Buenos Aires. Estudios Socioterritoriales, Revista de Geografía, (24). Recuperado de http://www.fch.unicen.edu.ar/ojs3.1.0/index.php/estudios-socioterritoriales/article/view/230 (consulta marzo de 2020).

Formiga, N. (1997). Transformaciones recientes en el espacio periurbano de Bahía Blanca. Revista Interamericana de Planificación, XXIX(114), 119-131.

García Ramón, M.D.; Tulla I Pujol, A. y Valdovinos Perdices, N. (1995). Geografía Rural. Colección Espacios y sociedades. Serie General, (10). Barcelona: Síntesis.

González Escobar, L.F. (2003). Estrategias corregimentales - eco -Políticas para la nueva ruralidad en Medellín. Seminario Internacional Mundo Rural: Transformaciones y perspectivas a la luz de la nueva ruralidad. Bogotá. Recuperado en http://www.bdigital.unal.edu. 
co/3368/1/LFG01-ECO.pdf (consulta abril de 2017).

González Plazas, J. (2006). Caracterización socioespacial actual del hábitat en la periferia urbana de Manizales. Revista de Arquitectura El Cable, (5). Colombia: Universidad Nacional de Colombia. Recuperado de: http://www.manizales.unal.edu.co/modules / unrev_el cable/ (consulta abril de 2009).

Hernández Montesinos, M.I. (2001). Estudio de las dinámicas agrarias y de las estrategias de los agricultores en el medio periurbano. Actas del IV Coloquio Hispano-Portugués de Estudios Rurales sobre La multifuncionalidad de los espacios rurales de la península Ibérica. Recuperado de sper.pt/oldsite/IVCHER/CD\%20COLOQUIO/isabelh.doc (consulta mayo de 2013).

Instituto Nacional de Estadística y Censos INDEC (2010). Población en viviendas particulares según área urbano-rural. Provincia de Buenos Aires. Año 2010. Buenos Aires: Ministerio de Economía. Recuperado de http://www.estadistica.ec.gba.gov.ar/dpe/images/Poblacion_en_viviendas_particulares_urbano_rural_2010.xlsx (consulta diciembre de 2014).

Jorquera Limón, R. y Gálvez Andrade, J. (2018). Vulnerabilidad laboral y capital humano en contextos Periurbanos-Rururbanos (pp. 73-94). En R. Jorquera Limón y A. Avendaño Enciso (Coords.) Instituciones y actores sociales. Perspectivas de la investigación sociológica en la Universidad de Sonora. México: Universidad de Sonora. DOI http://doi. org/10.29410/QTP.18.09

Jungemann, B. (2008). Organizaciones sociales y anclaje territorial escenarios y componentes de la transformación socioterritorial y local en Venezuela. Cuadernos del Cendes, 25(67), 1-34. Recuperado de http://www.redalyc.org/pdf/403/40306702.pdf (consulta enero 2015).

Katzman, R. (2005). Activos, vulnerabilidad y estructura de oportunidades. Enfoque AVEO (pp. 54-77). En R. Canudas y M. Lorenzelli (Coords.) Inclusión social una perspectiva para la reducción de la pobreza. Honduras: INDES. Recuperado de: https://publications.iadb.org/publications/spanish/document/Inclusi\%C3\%B3n-social-Una-perspectiva-para-la-reducci\%C3\%B3n-de-la-pobreza.pdf (consulta julio de 2020).

Lindón, A. (2002a). La construcción social del territorio y los modos de vida en la periferia metropolitana. Territorios, (7), 27-41. Recuperado de: https://revistas.urosario.edu. co/index.php/territorios/article/view/5680/0 (consulta junio de 2020).

Lindón, A. (2002b). Trabajo, espacios de vida y cotidianidad. La periferia oriental de la ciudad de México. Scripta Nova, VI(119). Número extraordinario dedicado al IV Coloquio Internacional de Geocrítica (Actas del Coloquio). Recuperado de http://www. ub.edu/geocrit/sn/sn119-56.htm (consulta enero de 2012).

Lindón, A. (2003). La miseria y la riqueza de la vida cotidiana en la ciudad: el pensamiento de Lefebvre. Litorales: Teoría, método y técnica en geografía y otras ciencias sociales, 2(3). Recuperado de http://repositorio.filo.uba.ar/handle/filodigital/8141 (consulta febrero de 2013).

Lindón, A. (2005). Figuras de la territorialidad en la periferia metropolitana: topofilia y topofobias (pp. 145-172). En R. Reguillo y M. Godoy (Coords.) Ciudades translocales: espacios. Flujo. Representación. Perspectivas desde las Américas. Guadalajara: Social Science Research Council- ITESO.

Martínez Borrego, E. (2008). Nueva relación rural-urbana: globalización y transformaciones socioespaciales en los Altos de Morelos, México. Secuencia, (80), 129-166. DOI https://doi.org/10.18234/secuencia.v0i70.1033

Méndez Lemus, Y. y Vieyra Medrano, A. (2012). Expansión periférica y medios de vida 
agropecuarios: Una perspectiva de análisis del rol del capital social en la adaptación de los sistemas agropecuarios a la periurbanización. Congreso internacional de ecología urbana. Desafíos y escenarios de desarrollo para las ciudades latinoamericanas. Buenos Aires.

Moraga López, G. (2011). Geografía cultural e identidad territorial: El caso de lacomunidad de Cabuya, distrito de Cóbano, Puntarenas, 2009. Revista Geográfica de América Central, (46), 131-154. Recuperado de http://www.revistas.una.ac.cr/index.php/geografica/article/view/3295 (consulta junio de 2020).

Moreno Mata, A.; Cárdenas Nielsen, A. y Sánchez del Toro, G. (2018). Procesos perirubanos, desigualdad social y segregación residencial en la zona metropolitana de San Luis Potosí, 1990-2015. En A. Vieyra, Y. Méndez Lemus y J. Hernández Guerrero (Coords) Procesos periurbanos: desequilibrios territoriales, desigualdades sociales, ambientales y pobreza. México: Centro de investigaciones en geografía ambiental, Universidad $\mathrm{Na}$ cional autónoma de México. Recuperado de https://www.researchgate.net/publication/330714765_Procesos_periurbanos_desigualdad_social_segregacion_residencial (consulta junio de 2020).

Municipalidad de Bahía Blanca, Secretaria de Planificación (2011). Plan director del periurbano bahiense y desarrollo de centros de interés turístico ambiental en el partido de Bahía Blanca. Concurso de propuestas para acceder al cupo urbanizador. Base, pliego de condiciones y especificaciones. Bahía Blanca: Municipalidad de Bahía Blanca. Recuperado de http://bahiablanca.gov.ar/subidos/agencia-urbana/Pliego-Concurso-de-Propuestas -2011.p d f (Consulta en marzo de 2012).

Municipalidad de Bahía Blanca (2009). Plan de desarrollo local Bahía Blanca. Estudio 1. EE 289. Informe final, consultor $N^{\circ} 7$ Susana Zinger. Bahía Blanca: MBB. 220 pp.

Nates Cruz, B. (2018). Territorialidades rururbanas o rururbanidad contemporánea. Revista de Antropología y Sociología: Virajes, 20(1), 5-12.

Pérez de Armiño, K. (1999). Vulnerabilidad y desastres. Causas estructurales y procesos de la crisis de África. Cuadernos de Trabajo de Hegoa, (24). Recuperado de https://ojs.ehu. eus/index.php/hegoa/article/view/10802 (consulta enero de 2017).

Pizarro, R. (2001). La vulnerabilidad social y sus desafíos: una mirada desde América Latina. CEPAL SERIE Estudios estadísticos y prospectivos, (6). Recuperado de https://repositorio. cepal.org/bitstream/handle/11362/4762/S0102116_es.pdf?sequence=1\&isAllowed=y

Riou, Y. (2011). Representations, participation, ancrage, identite: quatre piliers pour penser l'inscription territoriale. Le cas du Berry. Tesis doctoral. Recuperado de https://tel.archives-ouvertes.fr/tel-00730366 (consulta febrero de 2018).

Sánchez Torres, D.M. (2018). Abordajes teórico-conceptuales y elementos de reflexión sobre rururbanización desde los estudios territoriales. Revista de Antropología y Sociología: Virajes, 20(1), 15-35. DOI 10.17151/rasv.2018.20.1.2

Sauri Pujol, D. (2003). Tendencias recientes en el análisis geográfico de los riesgos ambientales. Areas Revista Internacional de Ciencias Sociales, (23), 17-30.

Sereno, C.; Santamaría, M. y Santarelli, S. (2010). El rururbano: espacio de contrastes, significados y pertenencia. Ciudad de Bahía Blanca, Argentina. Cuadernos de Geografía, (19), 41-57. Recuperado de https://revistas.unal.edu.co/index.php/rcg/article/ view/16844/36688

Stadel, C. (2008-2009). Vulnerabilidad, resistividad en el campesinado rural de los Andes tropicales. Anuario americanista europeo, (6-7), 185-200. Recuperado de https://dial- 
net.unirioja.es/servlet/articulo?codigo=3403389 (consulta septiembre de 2013).

Tacoli, C. (2003). Impactos sobre los modos de vida y estrategias económicas en la interfase periurbana: un relevamiento de los temas de debate. Cuadernos del Cendes, 53(53), 39-49. Recuperado de http://ve.scielo.org/scielo.php?script=sci_arttext\&pid=S1012-25082003000200004 (consulta septiembre de 2013).

Urriza, G. (2018). Expansión urbana en ciudades intermedias de crecimiento demográfico bajo: el caso de Bahía Blanca, Argentina. X Seminario Internacional de Investigación en Urbanismo, Barcelona-Córdoba. Barcelona: DUOT (consulta febrero de 2020).

Wilches-Chaux, G. (1993). La vulnerabilidad global (pp. 9-50). En A. Maskrey (Ed.) Los desastres no son naturales. Colombia: La Red, Tercer Mundo Editores. Recuperado de https://www.desenredando.org/public/libros/1993/Idnsn/ (consulta en marzo de 2011).

Zinger, S.; Del Pozo, O. y de Gaetano, R. (1990). Bahía Blanca: análisis de la aptitud del medio natural para la expansión urbana. Revista Universitaria de Geografía, 4(1 y 2), 76-96.

Zuluaga Sánchez, G.P. (2005). Dinámicas territoriales en frontera Rural-urbana en corregimiento de Santa Elena, Medellín. Tesis de Maestría. Medellín, Universidad Nacional de Colombia. Escuela del hábitat. Facultad de arquitectura. Recuperado de http://www.bdigital.unal.edu.co/5019/ (consulta enero de 2017).

\footnotetext{
Claudia Sereno es Doctora en Geografía, título expedido por la Universidad Nacional del Sur (2017). Actualmente desempeña tareas docentes como Asistente exclusiva en las cátedras de Técnicas en Geografía y Metodología de la investigación Geográfica y Turística, en el Departamento de Geografía y Turismo de la Universidad Nacional del Sur. Participa en distintos proyectos de investigación y extensión universitaria. Las líneas de investigación en las que trabaja pertenecen a la Geografía urbana, en especial el estudio de los espacios de borde, a la Geografía cultural y a las Geografías emergentes de la Vida Cotidiana. Departamento de Geografía y Turismo. Universidad Nacional del Sur (UNS). 12 de octubre 991, oficina 07, int. 2907, (8000) Bahía Blanca, Buenos Aires, Argentina, csereno@uns.edu.ar, ORCID https://orcid.org/0000-0002-2986-6807
} 